\title{
Microfluidic-Based Study on the Activation and Evolution of Calcite Bio-Mineralization for Geotechnical Applications
}

\author{
Ariadni Elmaloglou'; Dimitrios Terzis, Ph.D. ${ }^{2}$; Pietro De Anna, Ph.D. ${ }^{3}$; Lyesse Laloui, Ph.D. ${ }^{4}$; \\ Stéphane Mahé, Ph.D. ${ }^{5}$; and Filippo Miele ${ }^{6}$ \\ ${ }^{1}$ Laboratory of Soil Mechanics, Swiss Federal Institute of Technology, Lausanne (EPFL). E- \\ mail: ariadni.elmaloglou@epfl.ch \\ ${ }^{2}$ Laboratory of Soil Mechanics, Swiss Federal Institute of Technology, Lausanne (EPFL). E- \\ mail: dimitrios.terzis@epfl.ch \\ ${ }^{3}$ Laboratory of Soil Mechanics, Swiss Federal Institute of Technology, Lausanne (EPFL). E- \\ mail: lyesse.laloui@epfl.ch \\ ${ }^{4}$ Faculty of Geosciences and Environment, Univ. of Lausanne (UNIL). E-mail: \\ pietro.deanna@unil.ch \\ ${ }^{5}$ Faculty of Geosciences and Environment, Univ. of Lausanne (UNIL). E-mail: \\ stephane.mahe@unil.ch \\ ${ }^{6}$ Faculty of Geosciences and Environment, Univ. of Lausanne (UNIL). E-mail: \\ filippo.miele@unil.ch
}

\begin{abstract}
The field of geotechnics is moving fast towards benefiting from new methods and tools to improve the understanding of couplings among complex transport, chemical and biological phenomena. Calcite bio-mineralization, result of bio-grouting, stands out as such a problem where solute and solid transport phenomena, cell attachment, and cell/crystal growth mechanisms hold the key towards the formation of new, improved geo-materials. In the present study, focus is put on the real-time monitoring of the critical evolution of calcite precipitation within long trajectories in microfluidic chips. The total transport path, across which these phenomena are captured and interpreted, ranges between 1 and 1.5 meters to evaluate at which extend calcite crystal growth and deposition varies along the infiltrated porous chips. Results reveal varying number and sizes of crystals which precipitate across the flow path while qualitative characteristics are also discussed. Overall, the study aims to shed light into the previously underexplored, activation of the bio-cementation reaction, which governs nucleation, transport, and growth of calcite mineral binders and, therefore, influences the mechanical response of geo-materials subjected to bio-grouting applications.
\end{abstract}

\section{INTRODUCTION}

The principle of tailoring, at will, material properties to improve the mechanical behavior of soils through compaction or cement grouting dates back to the 60s. During the past decade, a new concept was brought into surface, pushing the boundaries of grouting towards new frontiers. This is no other than the concept of biologically-induced soil cementation, which is most commonly referred to as Microbial Induced Calcite Precipitation (MICP) or simply bio-grouting (DeJong et al. 2006, van Paassen et al 2010, DeJong et al. 2013, Jiang et al. 2016). The fundamentals of this technique, as well as the overall progress and pivotal points in this decadelong path will not be further treated in this paper but can be found in the recent review work by Terzis and Laloui (2019). The MICP technique has been under the radar of researchers and practitioners in geo-technical and geo-environmental engineering (Fauriel \& Laloui 2012, 
Dejong et al. 2013, Terzis et al. 2016, Terzis and Laloui 2018) with specific focus being put on a series of conditions, which have been found to influence the result of MICP. Some of these parameters are: (i) the bacteria cell concentration, (ii) $\mathrm{pH}$ condition, (iii) salinity, (iv) temperature, (v) degree of saturation and (vi) chemical composition of the reactive fluids which are involved in the process.

The study presented herein does not aim to investigate such factors, which have been found to affect the properties of calcite binders, i.e. the end product of this biologically mediated process. Instead, this work mobilizes a novel, four-dimensional observation method to reveal real-time data on the nucleation of calcite precipitates and their transport and growth mechanisms till the formation of interparticle bonds.

We provide a qualitative and quantitative description of certain precipitation behaviors to understand the evolution of bond geometries with respect to the crucial overall bond content along long flow trajectories in the meter-scale. This investigation takes place via time-lapse video microscopy to capture the evolution of MICP within a Polydimethylsiloxane (PDMS) (Yang et al. 2010, Jiménez-Martínez 2015) physical model of a flow channel. This type of channel is chosen to observe the reactive and transport mechanisms under laminar flow conditions. Detailed features on the setup will be discussed in the following section.

\section{MATERIALS AND METHODS}

Two microfluidic chips are used, with their dimensions presented in Table 1. To facilitate the presentation of the study, we will refer to the two chips as empty channel and porous channel, respectively. Specific focus is put on quantified results from the empty channel and the qualitative characterization on the porous channel. The rectangular section is chosen to allow crystals to grow on the bottom of the channels. During the experiments the microfluidic chips are placed horizontally on the stage of a fully automated, inverted microscope and large images with focus on the bottom of the channels are captured with a colored camera at multiple positions along the path and multiple time intervals. The long flow paths are chosen to determine spatial variations in the mass and characteristics of the precipitates under unobstructed (empty channel) and hindered (porous channel), reactive flow. This three-dimensional path is further investigated with respect to time, to evaluate the evolution of calcite growth with respect to the treatment conditions.

Table 1. Geometry of microfluidic channels

\begin{tabular}{ccccc}
\hline $\begin{array}{c}\text { microfluidic } \\
\text { channels }\end{array}$ & Width $(\mathbf{m m})$ & Height $(\mathbf{m m})$ & $\begin{array}{c}\text { Flow path } \\
\text { length }(\mathbf{m m})\end{array}$ & $\begin{array}{c}\text { Grain diameter } \\
(\mathbf{m m})\end{array}$ \\
\hline 1 empty channel & 1 & 0.1 & 1576 & - \\
2 porous channel & 3 & 0.05 & 982 & 0.15
\end{tabular}

Results on the porous channel are of specific interest given that flow conditions are altered substantially due to the presence of grains of diameters equal to $150 \mu \mathrm{m}$. Therefore, the ideal, laminar flow assumed for the empty channel is now replaced by a flow network within a porous structure (porosity $=0.6$ ) with grains representing 3D cylindrical pillars, which run across the channel's height $(50 \mu \mathrm{m})$ and represent obstacles. Grains are expected to alter the flow conditions and result into partial or complete clogging of the inter-pillar space.

Figure 1 illustrates the empty chip in its post-biocementation phase of a total flow path of $1.576 \mathrm{~m}$. Table 2 shows the recipies of the bio-stimulation and bio-mineralization solutions, 
which were introduced in the microfluidic chip according to the treatment pattern presented in Table 3. More precisely, a bio-stimulation solution, containing urea and tryptic soy broth is firstly introduced into the chip and allowed for a 20-hour period (retention time), during which Sporosarcina Pasteurii (S. Pasteurii) grow within the chip from an initial concentration of $10^{6}$ $\mathrm{cfu} / \mathrm{mL}$ to a final concentration of $10^{8} \mathrm{cfu} / \mathrm{mL}$. The bio-stimulation phase is followed by three bio-mineralization cycles. Each bio-mineralization batch is injected during 1 hour with a constant effective flow rate of $0.5 \mu \mathrm{L} / \mathrm{sec}$, which is imposed by a syringe pump (Harvard apparatus), and allowed to react for 6-20 hours. The injected volume per batch is ten times the chip's volume to ensure complete saturation with fresh media and observe the nucleation process under continuous supply of reactants. Large images are captured at various intervals (1-20-40 minutes) during injection and retention periods with a resolution of $0.29 \mu \mathrm{m} /$ pixel. For comparison individual cells have a size of about 3-5 $\mu \mathrm{m}$.

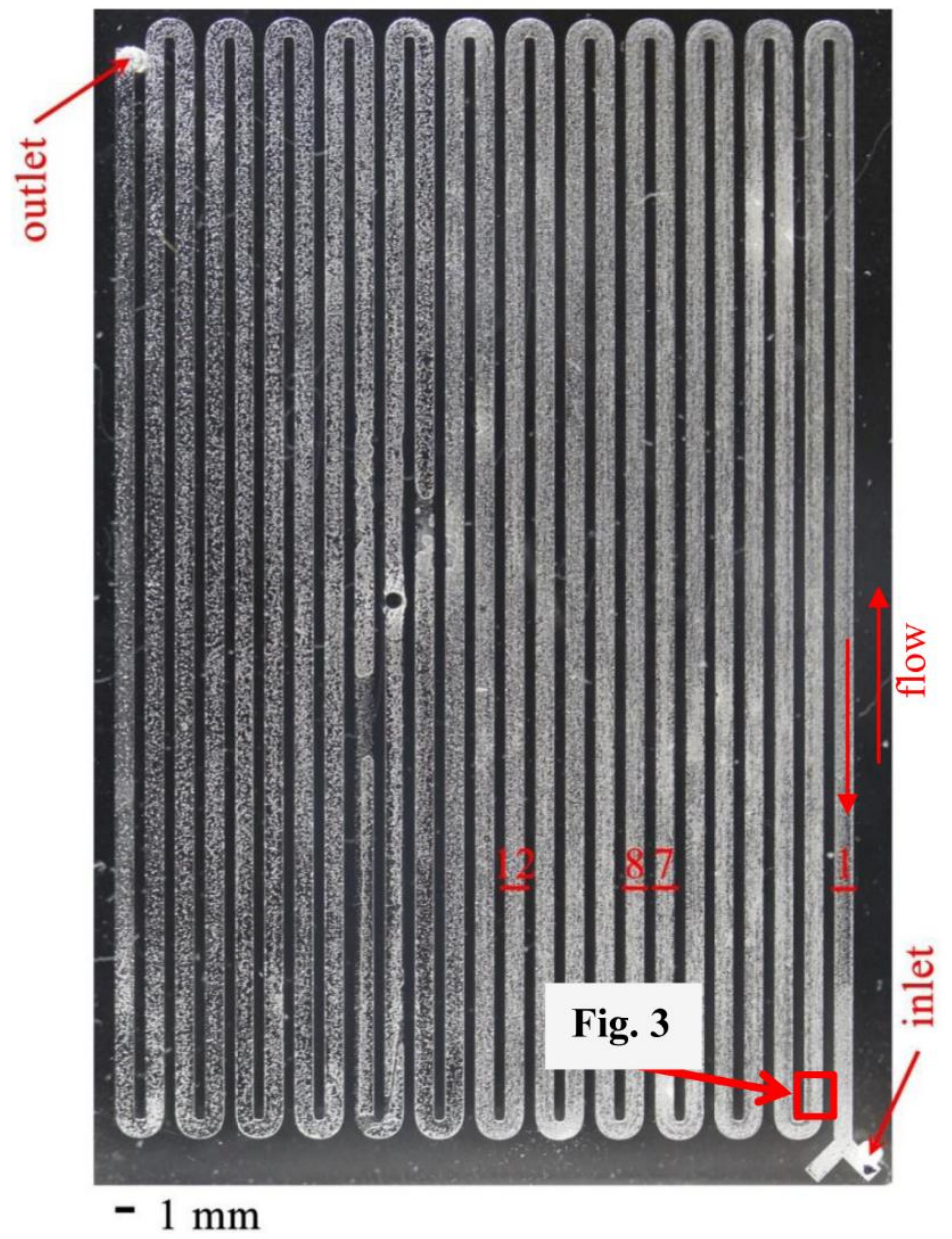

Figure 1. The empty microfluidic chip used to monitor calcite bio-mineralization across $1.576 \mathrm{~m}$ of flow path.

We postulate that potential discrepancies in the crystal distribution across the flow path will be attributed to: (i) the depletion of reactants since reaction is instantaneous upon introduction of a calcium $\left(\mathrm{Ca}^{2+}\right)$ source to the carbonate-rich $\left(\mathrm{CO}_{3}{ }^{2-}\right)$ inlet source and (ii) the deposition of calcite $\left(\mathrm{CaCO}_{3}\right)$ nuclei on the bottom of the channel as they grow larger. Another hypothesis is that nucleation takes place as epicellular precipitation (Terzis et al., 2016) in the form of 
amorphous $\mathrm{CaCO}_{3}$ particles. In this metastable condition cells carrying $\mathrm{CaCO}_{3}$ nuclei can be still transported across the flow path. These act as nucleation sites for the aggregation and further growth of particles. As nuclei grow bigger, and thus heavier, they precipitate on the bottom of the flow channel and occupy their final position.

Table 2. Recipies of Bio-stimulation and Bio-mineralization Solutions

\begin{tabular}{ccccc}
\hline & $\begin{array}{c}\text { Urea } \\
(\mathbf{m m o l} / \mathrm{L})\end{array}$ & $\begin{array}{c}\text { Tryptic Soy } \\
\text { Broth }(\mathrm{g} / \mathrm{L})\end{array}$ & $\begin{array}{c}\text { Calcium Chloride } \\
(\mathbf{m m o l} / \mathrm{L})\end{array}$ & $\begin{array}{c}\text { Initial } \\
\text { Concentration of } \\
\text { Sporosarcina } \\
\text { Pasteurii }(\mathbf{c f u} / \mathbf{m L})\end{array}$ \\
\hline $\begin{array}{c}\text { Bio-stimulation } \\
\text { Solution }\end{array}$ & 330 & 10 & - & $10^{6}$ \\
$\begin{array}{c}\text { Bio-mineralization } \\
\text { Solution }\end{array}$ & 250 & 3 & 250 & - \\
\hline Solution
\end{tabular}

Table 3. Treatment pattern applied to the empty channel

\begin{tabular}{ccccc}
\hline $\begin{array}{c}\text { Injection } \\
\text { cycle }\end{array}$ & Treatment Solution & $\begin{array}{c}\text { Volume } \\
\text { injected* }\end{array}$ & $\begin{array}{c}\text { Injection } \\
\text { duration [h] }\end{array}$ & $\begin{array}{c}\text { Retention } \\
\text { time [h] }\end{array}$ \\
\hline 1 & $\begin{array}{c}\text { Biological Solution } \\
2\end{array}$ & 1 & 0.1 & 20 \\
3 & Bio-mineralization Solution & 10 & 1 & 6 \\
4 & Bio-mineralization Solution & 10 & 1 & 20 \\
Bio-mineralization Solution & 10 & 1 & 20
\end{tabular}

Obtained images cover the time-lapse since initial bacteria cell introduction in urea-tryptic soy broth solution, to their growth and subsequent flush-out due to the injection of the following batch of urea-calcium-tryptic soy broth solution until formation of calcite particles. Images are analyzed using an image segmentation method to distinguish numbers of cells, numbers of calcite particles and their sizes implemented in MATLAB. The 2D areas measured through image processing are considered as the diameters of spherical particles with a density of 2.71 $\mathrm{g} / \mathrm{cm}^{3}$ to express quantification in terms of precipitated mass of calcite crystals.

\section{RESULTS}

In Figure 1, which illustrates the empty channel, as aforementioned, calcite crystals can be clearly seen accumulating in the first half of the flow path, compared to the second half and the outlet. The bubble located close to the middle of the shown chip represents the sole artifact generated during the manufacturing of the PDMS chip. A gradually reducing concentration can be observed even with the naked eye. Figure 2 presents four cross sections from the clusters 1, 7, 8 and 12 (see figure 1). These images are obtained through micro-computed X-Ray ( $\mu$-CT) tomography and serve as an additional way of validating the spatial homogeneity of crystals. $\mu$-CT images have a resolution of $10 \mu \mathrm{m} /$ pixel due to the large size of the analyzed microfluidic chip. Figure 2 validates the decreasing concentration of crystals along the flow path. More precisely, calcite particles are found to grow larger in the beginning of the reactive flow trajectory (section 1), while exhibiting smaller sizes in the middle of the channel (cluster 12)

Table 4 presents the mass of precipitated calcium carbonate during three bio-mineralization cycles applied after the initial bacteria introduction and growth. It should be noted that time intervals are counted staring from the time that the microfluidic channel is saturated with the 
biological solution $(\mathrm{t}=0)$ and include duration of injection and retention periods. We focus on a segment of the microfluidic channel which is shown with a square in Figure 1. Observations on this sub-domain of the flow path are illustrated in Figure 3 for the respective time points $t_{1}, t_{2}, t_{3}$, $\mathrm{t}_{4}$.

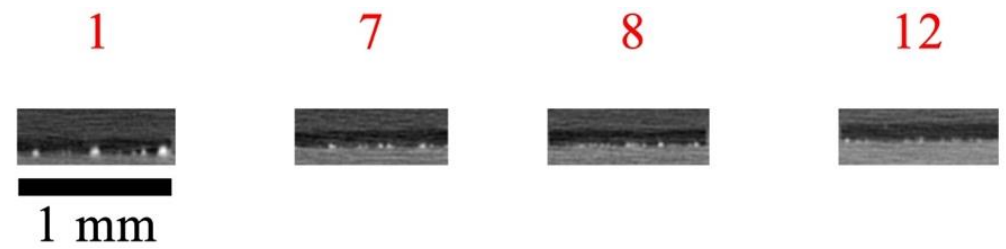

Figure 2. Four representative sections obtained through $\mu$-CT showing calcite particles (white) precipitated and the bottom of the empty channel (dark).

Table 4. Mass of precipitated calcium carbonate calculated for an image of dimensions 0.73 mm x 0.73 mm (Figure 3)

\begin{tabular}{ccc}
\hline Time & Bio-mineralization Phase & $\begin{array}{c}\text { Calcium carbonate } \\
\text { mass }(\boldsymbol{\mu g})\end{array}$ \\
\hline $\mathrm{t}_{1}=21 \mathrm{~h}$ & End of injection of $1^{\text {st }}$ batch & 3.5 \\
$\mathrm{t}_{2}=28 \mathrm{~h}$ & End injection of $2^{\text {nd }}$ batch & 15.9 \\
$\mathrm{t}_{3}=49 \mathrm{~h}$ & End injection of $3^{\text {rd }}$ batch & 25 \\
$\mathrm{t}_{4}=69 \mathrm{~h}$ & End of observations & 27.2
\end{tabular}

Figure 3 reveals immediate precipitation of crystals $\left(t_{1}=21 \mathrm{~h}\right)$, as soon as the first batch of the bio-mineralization solution flows through the channel which was previously filled with cells in a $\mathrm{CO}_{3}{ }^{2-}$-rich environment (result from the $20 \mathrm{~h}$ retention time in urea-tryptic soy broth). Black dots represent cell debris and epicellular precipitation is observed. In the following 6 hours, the first batch is allowed to react within the channel and crystals grow to reach a total mass of $15.9 \mu \mathrm{g}$ for the investigated volume equal to $0.054 \mathrm{~mm}^{3}$. Between $\mathrm{t}_{2}-\mathrm{t}_{3}$ (20h retention time for the biomineralization solution) crystals grow to reach a total mass of $25 \mu \mathrm{g}$. At $\mathrm{t}_{4}=69$ hours, after 20 hours of retention period for the third batch of bio-mineralization solution, crystal formation slows down significantly, and only an additional $2.2 \mu \mathrm{g}$ of calcite mass is produced. This is attributed to the complete wash-out of ureolytic cells observed following the injection of the $1^{\text {st }}$ batch of bio-mineralization solution.

Figure 4 illustrates the Probability density function (PDF) which expresses the normalized distribution of individual crystals with respect to their diameters. While crystals are found to predominantly yield sizes of $5 \mu \mathrm{m}$, a gradual shift of the share of particles yielding larger diameters is observed with respect to time and number of injected batches. The image in Figure 4 shows calcite particles of $5 \mu \mathrm{m}$, larger particles which reach $50 \mu \mathrm{m}$ and bacteria cells. It should be noted that the obtained resolution of images is $0.29 \mu \mathrm{m} /$ pixel, as aforementioned, and the minimum calcite crystal size captured is of $1 \mu \mathrm{m}$, result of epicellular precipitation.

Surface and textural observations on calcite crystals are obtained through Scanning Electron Microscopy (SEM) on the precipitates obtained when ureolytic cells are allowed to react with the bio-mineralization solution outside the chip, but under identical conditions as those prescribed to the PDMS channel. Direct SEM observations on crystals from the chip is not possible since this would require destructive methods to obtain samples of calcite and significant level of 
disturbance to their condition. To facilitate, therefore, the comparison between the quantified data of Figure 4, we present in Figure 5 the SEM observations on pure calcite crystals which are found to reach sizes of $50 \mu \mathrm{m}$ for individual crystals (white circle), $100 \mu \mathrm{m}$ for crystalline aggregates (black circle) and 10-20 $\mu \mathrm{m}$ for the smaller individual particles (arrows).
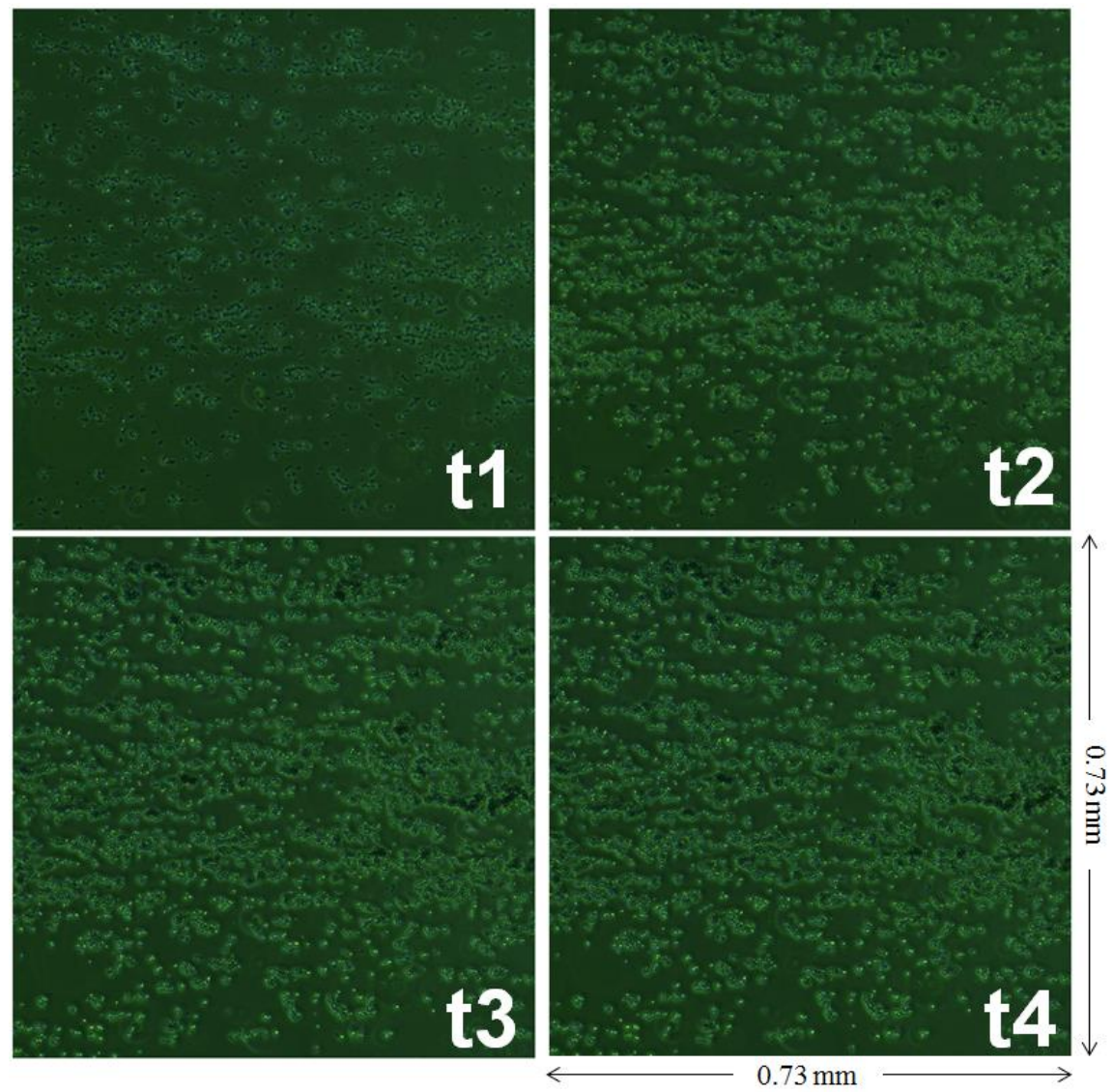

Figure 3. Time-lapse observations on a $0.73 \times 0.73 \mathrm{~mm}$ section of the flow path (square in Figure 1) between three batches of injected bio-mineralization solutions.

A series of qualitative characteristics is obtained for the case of flow within the porous chip, where 3D pillars alter the flow path during injection of the bio-mineralization batches. Figure 6 illustrates streamlines (shown in arrows) appearing as soon as the bio-mineralization solution flows within the porous channel and bacteria cells are beginning to yield calcium carbonate precipitates on their surface until cell and crystal deposition occurs on the pillars' surface. One should consider that the main difference between the empty and porous channel is the presence of the 3D pillars which alter the laminar flow postulated for the empty channel. Streamlines are therefore the result of the complex reactive and transport flow occurring within the chips. These streamlines are found to "feed" larger aggregates with cells and cell debris covered in calcite nuclei, resulting in the formation of nucleation sites for the mineralization of calcite particles, as captured in the time-lapse of Figure 6. The study of the role of these streamlines in the overall process of reactive transport will be the specific focus in a next work by the authors. 




Figure 4. Calcite probability density function (PDF) with respect to time events $\mathbf{t}_{1}-\mathrm{t}_{\mathbf{4}}$; inlet illustrates a representative subdomain of the studied channel where smaller and larger calcite particles are observed.

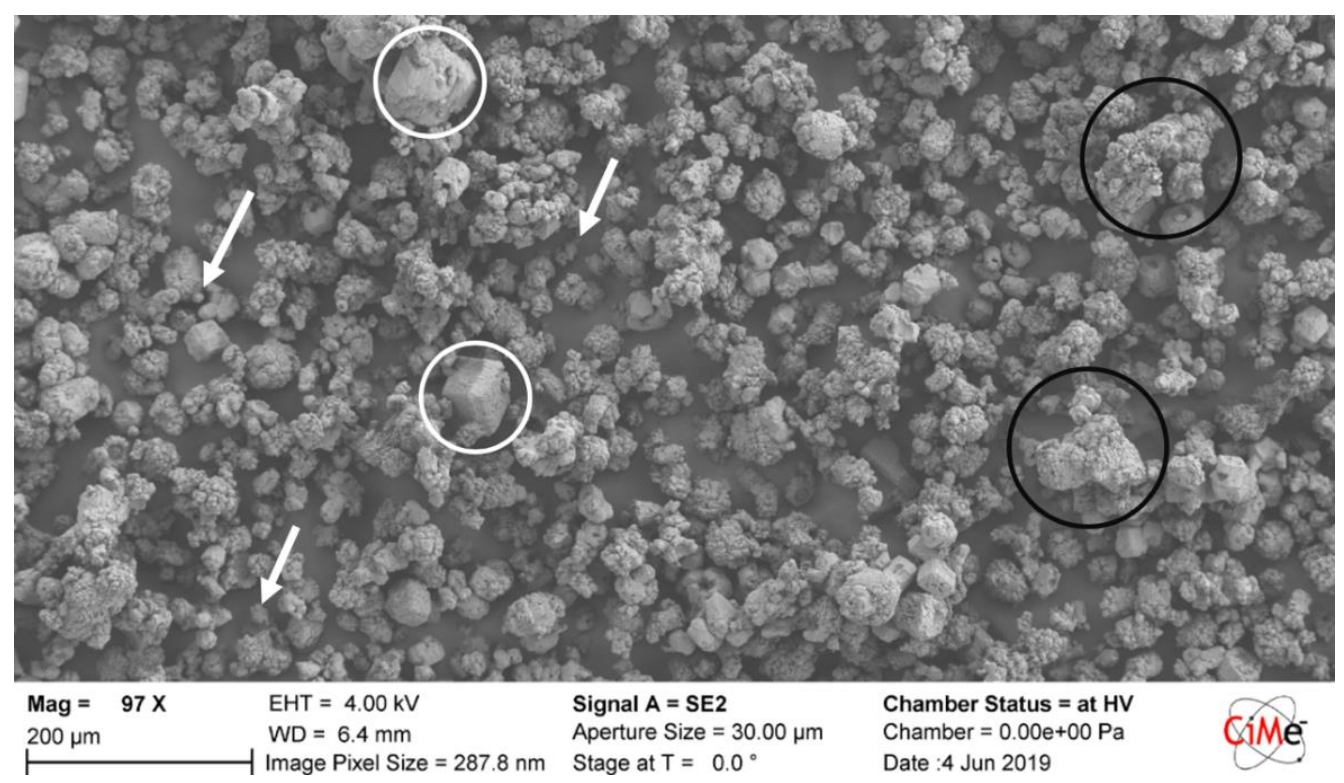

Figure 5. SEM observation on calcite crystals formed under no-flow conditions; large, individual particles (white circle); aggregates of particles (black circle); small, individual particles (arrows). 

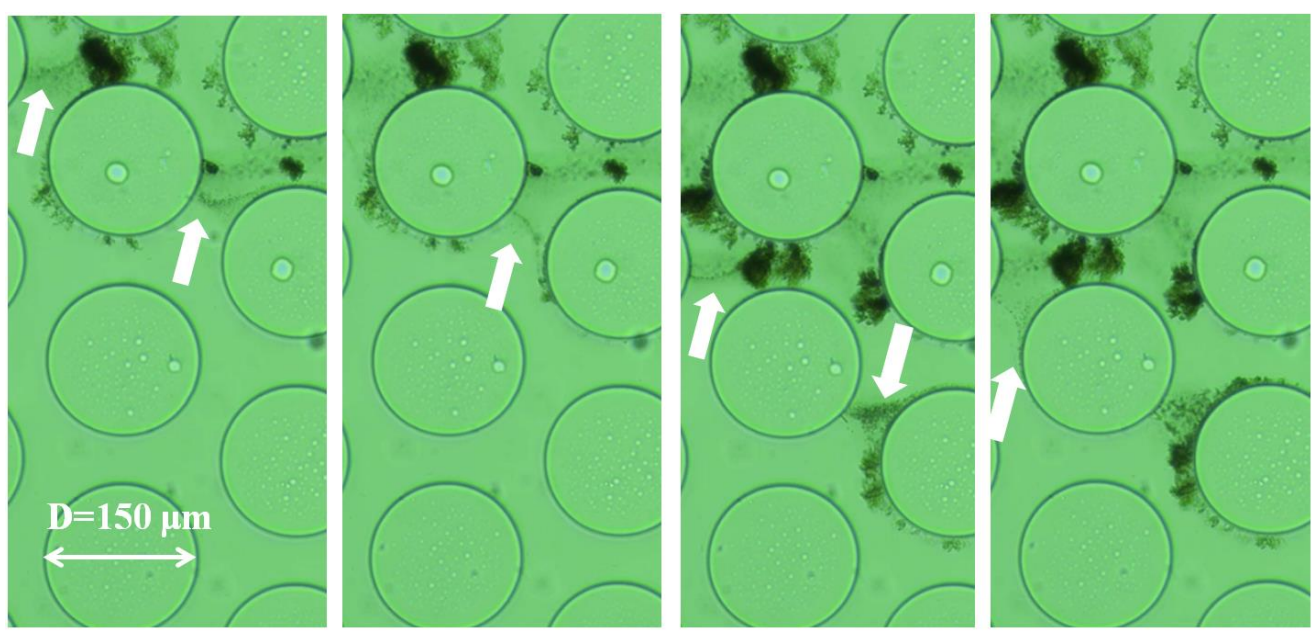

Figure 6. Timelapse between 90 seconds during injection of the bio-mineralization batch with nucleation site apparition crystal deposition via streamlines.

\section{CONCLUSION}

The present work introduces the use of microfluidic chips to study in real-time reactive and transport phenomena involved in calcite bio-mineralization, across a flow path of 1.5 meters. Time-lapse video microscopy is utilized to capture the evolution of micro-scale quantities and to contribute to a better understanding of the nucleation, transport and deposition phases in MICP starting from an empty flow channel where laminar flow conditions are assumed. Subsequently, we increase the complexity of the carried-out set-up and flow conditions by adding 3D microcolumns in a porous medium. Results reveal the evolution of the sizes of precipitated calcite and capture spatial variations in their mass along the flow path. A qualitative description of the transport and deposition of calcite nuclei on the surface of micro-pillars is provided through capturing streamlines which "feed" locations of particle growth. Such observations are expected to improve the design of MICP based studies and applications, by suggesting, for example, different injection steps and retention times to optimize the use of reactants and of ureolytic cells, while maximizing the efficiency of the application. Finally, capturing and quantifying reactivetransport parameters using such experimental tools becomes essential towards developing predictive modelling tools, dedicated to MICP, with the ultimate goal to attribute physical meaning into parameters used in such theoretical and numerical approaches.

\section{AKNOWLEDGEMENTS}

This project has received funding from the European Research Council (ERC) under the European Union's Horizon 2020 research and innovation programme (grant agreement No 788587).

\section{REFERENCES}

Dejong, J.T., Fritzges, M.B. and Nüsslein, K., 2006. Microbially induced cementation to control sand response to undrained shear. Journal of Geotechnical and Geoenvironmental Engineering, 132(11), pp.1381-1392.

Dejong, JT, Soga, K, Kavazanjian, E, Burns, S, van Paassen, L, AL Qabany, A, Aydilek, A, Bang, SS, Burbank, M, Caslake, LF, Chen, CY, Cheng, X, Chu, J, Ciurli, S, Esnault-Filet, A, 
Fauriel, S, Hamdan, N, Hata, T, Inagaki, Y, Jefferis, S, Kuo, M, Laloui, L, et al. 2013, 'Biogeochemical processes and geotechnical applications: Progress, opportunities and challenges' Geotechnique, vol. 63, no. 4, pp. 287-301.

Jiang, N.J., Soga, K. and Kuo, M., 2016. Microbially induced carbonate precipitation for seepage-induced internal erosion control in sand-clay mixtures. Journal of Geotechnical and Geoenvironmental Engineering, 143(3), p.04016100.

Jiménez-Martínez, J. et al. Pore-scale mechanisms for the enhancement of mixing in unsaturated porous media and implications for chemical reactions. Geophys Res Lett. 42(13), 5316-5324 (2015).

Terzis, D. and Laloui, L., 2018. 3-D micro-architecture and mechanical response of soil cemented via microbial-induced calcite precipitation. Scientific reports, 8(1), p.1416.

Terzis, D., \& Laloui, L. (2019). A decade of progress and turning points in the understanding of bio-improved soils: A review. Geomechanics for Energy and the Environment, 19, 100116.

Terzis, D., Bernier-Latmani, R., \& Laloui, L. (2016). Fabric characteristics and mechanical response of bio-improved sand to various treatment conditions. Géotechnique Letters, 6(1), 50-57.

van Paassen, L.A., Ghose, R., van der Linden, T.J., van der Star, W.R. and van Loosdrecht, M.C., 2010. Quantifying biomediated ground improvement by ureolysis: large-scale biogrout experiment. Journal of geotechnical and geoenvironmental engineering, 136(12), pp.1721 1728.

Yang, W. et al. Fabrication of a Hydrophilic Poly (dimethylsiloxane) Microporous Structure and Its Application to Portable Microfluidic Pump. Jpn J Appl Phys. 49(6S), 06GM01 (2010). 